\title{
Originals
}

\section{Increased Glomerular Permeability to Albumin Induced by Exercise in Diabetic Subjects*}

\author{
G. C. Viberti, R. J. Jarrett, M. McCartney, and H. Keen \\ Unit for Metabolic Medicine, Department of Medicine, Guy's Hospital Medical School, London, England
}

Summary. The urinary excretion of albumin was measured in insulin-dependent diabetics under ordinary conditions of life and in response to exercise. Possible mechanisms of exercise induced albuminuria in diabetics were also investigated. Under ordinary conditions of life the insulin-treated diabetics, as a group, had a higher mean urinary albumin excretion than normal controls; however, half of the diabetics had albumin excretion rates within the control range. A given exercise load $(600 \mathrm{kpm} / \mathrm{min}$ for $20 \mathrm{~min})$ produced an exaggerated albumin excretion in diabetics, particularly evident in the post-exercise period. The elevated urinary albumin excretion was due to an increased transglomerular passage of albumin, not to reduced tubular reabsorption. The increase was not associated with differences in blood pressure or urine flow between controls and diabetics. This exercise test has proved to be a suitable provocation test to unmask abnormalities in the glomerular handling of albumin that might not be recognisable at rest.

Key words: Diabetic nephropathy, albumin, $\beta_{2}$-microglobulin, exercise, hyperglycaemia, microangiopathy.

The specific renal complication of diabetes mellitus, diabetic nephropathy, usually becomes clinically manifest with the appearance of proteinuria, predominantly albuminuria. In recent years investigators have concerned themselves with earlier changes of renal structure and function in diabetics without proteinuria as measured by standard clinical tests. The

\footnotetext{
* Presented in part at the 12th Annual Meeting of the European Association for the Study of Diabetes, Helsinki, 1976
}

application of a sensitive assay for albumin revealed a significant increase in mean urinary albumin excretion in Type II diabetics newly detected in a population survey [1] and in newly diagnosed juvenile diabetics [2]. Findings in established, treated diabetics are, however, variable; some authors have reported increased [3] and others normal [2] albumin excretion rates in diabetics without clinically detectable proteinuria. Most studies of urinary albumin excretion in diabetics have been performed under comparatively basal, 'unstressed' conditions. Provocative stimuli might be expected to bring to light minimal abnormalities of renal function and possibly unmask changes undetectable at rest. Thus, Mogensen [4] studied the urinary albumin excretion in response to exercise and found that a given exercise load produced an elevation of urinary albumin excretion rates in diabetics, but not in normal controls.

We have studied the urinary albumin excretion in insulin-dependent diabetics without clinical proteinuria under ordinary conditions of life and in response to exercise and have also investigated the possible mechanisms of exercise albuminuria in diabetics.

\section{Materials and Methods}

Nine healthy control male subjects and 16 insulindependent diabetic men, all without clinically evident proteinuria (i.e. negative to Albustix) were studied (see Tables 1 and 2). None had a history of renal disease; all had sterile urine on culture; all were normotensive. The diabetics were receiving insulin but neither they nor the control subjects were taking any other drug. None of the controls had a first degree family history of diabetes. None of the diabetics had either somatic or autonomic neuropathy as assessed 
Table 1. Physical and clinical characteristics of control subjects

\begin{tabular}{llllll}
\hline \multicolumn{5}{c}{ Control Subjects } \\
\cline { 2 - 6 } $\begin{array}{l}\text { Sub- } \\
\text { ject }\end{array}$ & Age & $\begin{array}{l}\text { Height } \\
\mathrm{cm}\end{array}$ & $\begin{array}{l}\text { Weight } \\
\mathrm{kg}\end{array}$ & $\begin{array}{l}\text { Body surface }^{\mathrm{a}} \\
\text { area m}^{2}\end{array}$ & $\begin{array}{l}\text { Blood glucoseb } \\
\mathrm{mmol} / 1\end{array}$ \\
\hline $\mathrm{A}$ & 31 & 180 & 71.5 & 1.90 & 4.2 \\
$\mathrm{~B}$ & 38 & 178 & 75 & 1.92 & 4.0 \\
$\mathrm{C}$ & 32 & 184 & 79 & 2.02 & 3.6 \\
$\mathrm{D}$ & 24 & 163 & 65 & 1.70 & 5.2 \\
$\mathrm{E}$ & 28 & 175 & 78 & 1.93 & 3.2 \\
$\mathrm{~F}$ & 44 & 172.5 & 68 & 1.80 & 3.7 \\
$\mathrm{G}$ & 22 & 187 & 79 & 2.04 & 3.3 \\
$\mathrm{H}$ & 22 & 173 & 62 & 1.74 & 4.0 \\
$\mathrm{I}$ & 47 & 167.6 & 66.7 & 1.75 & 4.8 \\
$\mathrm{~J}$ & 29 & 190 & 76.2 & 2.02 & 5.0 \\
\hline Mean & 32 & 177 & 72 & 1.88 & 4.1 \\
\pm SD & \pm 9 & \pm 8 & \pm 6 & \pm 0.12 & \pm 0.7 \\
\hline
\end{tabular}

a Documenta Geigy. Tables Scientifiques. Sixth edition, p. 642.

b Random post-breakfast sample taken in the morning of the exercise test.

E Did not collect the 24 hour specimen

D Did not complete the exercise. Has been excluded from the exercise test

Table 2. Physical and clinical characteristics of diabetic subjects

Diabetic Subjects

\begin{tabular}{|c|c|c|c|c|c|c|c|}
\hline Subject & $\stackrel{\infty}{<}$ & 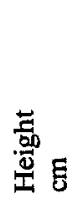 & 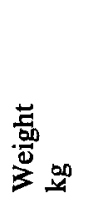 & 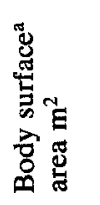 & 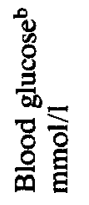 & 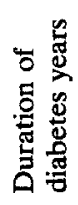 & 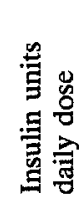 \\
\hline $\mathbf{K}$ & 23 & 175 & 65.4 & 1.80 & 14.9 & 15 & 64 \\
\hline $\mathrm{L}$ & 51 & 162 & 62.9 & 1.67 & 6.3 & 8 & 80 \\
\hline$\overline{\mathbf{M}}$ & 28 & 182 & 70.6 & 1.91 & 23.8 & 12 & 68 \\
\hline $\mathbf{N}$ & 46 & 180 & 75 & 1.94 & 20.2 & 17 & 40 \\
\hline $\mathrm{O}$ & 20 & 170 & 60.5 & 1.70 & 23.1 & 11 & 76 \\
\hline $\mathbf{P}$ & 47 & 173 & 66 & 1.73 & 6.9 & 13 & 50 \\
\hline$\emptyset$ & 25 & 168 & 64 & 1.72 & 18.2 & 15 & . 68 \\
\hline $\mathrm{Q}$ & 29 & 182 & 79.7 & 2.01 & 16.9 & 1 & 132 \\
\hline $\mathrm{R}$ & 26 & 181 & 67.4 & 1.86 & 13.4 & 3 & 32 \\
\hline S & 24 & 182 & 64.7 & 1.83 & 7.0 & 10 & 64 \\
\hline $\mathrm{T}$ & 25 & 180 & 69 & 1.87 & 11.0 & 9 & 88 \\
\hline $\mathrm{U}$ & 21 & 180 & 78.5 & 1.98 & 11.3 & 5 & 72 \\
\hline V & 29 & 185 & 62.5 & 1.83 & 7.7 & 0.4 & 44 \\
\hline W & 49 & 175 & 78 & 1.92 & 15.3 & 23 & 48 \\
\hline $\mathrm{X}$ & 31 & 180 & 71.5 & 1.90 & 13.7 & 21 & 56 \\
\hline$Y$ & 37 & 177 & 66 & 1.81 & 11.2 & 13 & 42 \\
\hline $\mathrm{Z}$ & 49 & 168 & 61 & 1.69 & 6.4 & 3 & 46 \\
\hline Mean & 33 & 176 & 68.3 & 1.83 & 13.4 & 10.5 & \\
\hline$\pm \mathrm{SD}$ & \pm 11 & \pm 6 & \pm 6 & \pm 0.10 & \pm 5.7 & \pm 6 & \\
\hline
\end{tabular}

a Documenta Geigy. Tables Scientifiques. Sixth edition, p. 642

b Random post-breakfast sample taken in the morning of exercise test

$\emptyset$ Did not manage the exercise. Has been excluded from the exercise test

Q Did not collect the $24 \mathrm{~h}$ specimen by standard clinical methods. Patients K, L, P, T, W and $X$ had mild background retinopathy. Patients $L$, $\mathrm{N}, \emptyset, \mathrm{R}, \mathrm{S}, \mathrm{X}, \mathrm{Y}$ and $\mathrm{Z}$ were on soluble insulin; $\mathrm{N}$ and $\mathrm{T}$ were on lente insulin and $\mathrm{K}, \mathrm{O}, \mathrm{P}, \mathrm{Q}, \mathrm{U}, \mathrm{V}$ and $\mathrm{W}$ were on a mixture of quick and intermediate or long acting insulin. The physical and clinical characteristics of all subjects are listed in Tables 1 and 2.

The $24 \mathrm{~h}$ collection of urine was made under ordinary conditions of life (i. e. at home or at work) usually during the day preceding the exercise test. The diabetics were all studied as outpatients and came to the hospital for the exercise tests which were begun at approximately 9.00 am and were performed at an ambient temperature of about $20^{\circ} \mathrm{C}$. The experimental conditions were kept as constant as possible since many environmental stimuli may influence renal function [5]. All subjects took their normal breakfast, avoiding tea or coffee, preceded in the diabetics by the usual morning dose of insulin. Fluid intake at home was not controlled, but subjects were asked not to drink after their breakfast.

All the subjects studied exercised at the same rate - $600 \mathrm{kpm} / \mathrm{min}$ - sitting upright on a bicycle ergometer. This exercise load has been previously reported [4] as likely to produce different responses in normal controls and diabetics. In the selection of our subjects we tried to avoid extreme differences of 'fitness'. All the diabetics were engaged in normal social, working and physical activities and we selected reasonably fit people who might be expected to manage the exercise, which is moderately strenuous.

On arrival at the laboratory the subjects voided completely and urine was then collected over the following three periods:

1. a one hour pre-exercise resting period in the sitting position immediately preceded and followed by a $300 \mathrm{ml}$ drink of tap water.

2. a $20 \mathrm{~min}$ exercise period on a bicycle ergometer.

3. a one hour post-exercise period in the sitting position.

Pulse rate and systolic B. P. were monitored every 10 min during the exercise test, B. P. by conventional sphygmomanometry (diastolic blood pressure is grossly under-estimated when measured with an external cuff during exercise and was not taken into consideration [6]).

The volume of each urine sample was measured and aliquots from each collection were stored deep frozen until analysis. A venous blood sample was drawn without stasis from an antecubital vein at the beginning of the resting period in all subjects for glucose determination. In 7 controls and in 10 diabetics creatinine concentration was also measured [7]; in 
these same subjects a second venous blood sample was taken 3 to 5 minutes after the end of the exercise for a further plasma creatinine determination. Creatinine concentration was also estimated in the resting and exercise urine specimens of these 7 controls and 10 diabetics. The calculated creatinine clearances were corrected to $1.73 \mathrm{~m}^{2}$ body surface area. Urinary albumin concentration was determined using a radioimmunoassay method, previously described [8]. Urinary $\beta_{2}$-microglobulin was also measured by a radioimmunoassay [9]. Albumin and $\beta_{2}$-microglobulin excretion rates were calculated from the concentration and the timed urine volume. Blood glucose was determined by the ferricyanide reduction method modified for the Autoanalyser. For statistical calculations the albumin and $\beta_{2}$-microglobulin rates were converted to $\log _{10}$ values because of their skewed distribution. Statistical analyses were performed using parametric tests for paired and unpaired data.

\section{Results}

\section{$24 \mathrm{~h}$ Collection}

Urine flow (mean $\pm \mathrm{SEM}$ ) was $1.3 \pm 0.2 \mathrm{ml} / \mathrm{min}$ in the controls and $1.4 \pm 0.1 \mathrm{ml} / \mathrm{min}$ in the diabetics. This difference was not statistically significant. Logalbumin excretion rates, shown in Figure 1, were significantly higher in the diabetics as a group ( $\mathrm{p}<$ 0.02 ), but 8 diabetics had excretion rates within the control range. No significant correlation was found in the diabetics between log-urinary albumin excretion and post-breakfast blood glucose, duration of diabetes, presence of retinopathy and daily insulin dose. However, the diabetics with higher excretion rates of albumin tended to have higher glucose values and higher daily insulin doses.

\section{Exercise Test}

Tables 3 and 4 show the individual results of urine flow, creatinine clearance and albumin and $\beta_{2}$-microglobulin excretion rate during rest, exercise and post-exercise periods in the controls and in the diabetics, respectively. The diabetics were divided into two subgroups according to their resting urinary albumin excretion - group 1 with resting albumin excretion rates within the control range, group 2 with albumin excretion rates above the control range. There were no significant differences in levels of blood glucose and frequency of retinopathy between the two diabetic groups. Urine flow at rest was similar in the controls and group 2 diabetics; although it

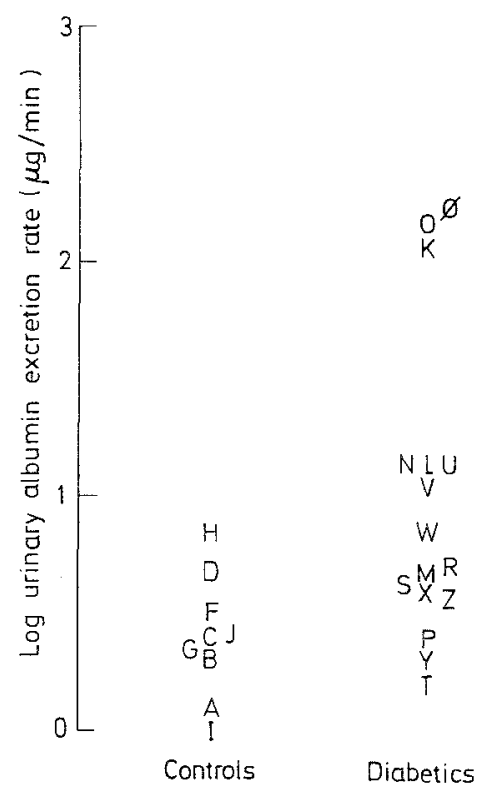

Fig. 1. 24-hour log. urinary albumin excretion rates in 9 controls and 16 diabetics

was higher in group 1 diabetics the difference was not statistically significant. During exercise and in the post-exercise period urine flow fell sharply in the diabetics $(\mathrm{p}<0.001$ and $<0.005$ respectively for group $1 ; \mathrm{p}<0.001$ and $<0.01$ respectively for group 2 ), whereas it did not change in the controls.

Creatinine clearance at rest did not differ between the controls and the diabetics although it tended to be higher in group 2. During exercise it decreased in 6 out of 7 controls $(p<0.05)$. In the diabetics it decreased in 2 out of 6 in group 1 and in all 4 in group 2, though the mean changes were not statistically significant. No correlation was found between changes in albumin excretion and changes in creatinine clearance during exercise.

The log-albumin excretion rate did not change significantly in the controls during the exercise and post-exercise periods. By contrast, in group 1 diabetics it increased significantly during exercise $(p<$ 0.05 ) and particularly in the post-exercise period ( $p$ $<0.01$ ). In group 2 diabetics the log-albumin excretion rate increased especially in the post-exercise period $(p<0.005)$; the increase during the exercise failed to reach statistical significance. Furthermore, the change in log-albumin excretion in the post-exercise period, compared with the resting values, was significantly greater in diabetics $(\mathrm{p}<0.01$ for groups 1 and 2) than in controls (Fig. 2). The $\log -\beta_{2}-\mathrm{mi}-$ croglobulin excretion rate was slightly, but not significantly, higher in the two groups of diabetics at rest compared with that of the controls. This small difference disappeared during exercise, when $\beta_{2}$-microglobulin excretion rates did not change in the con- 


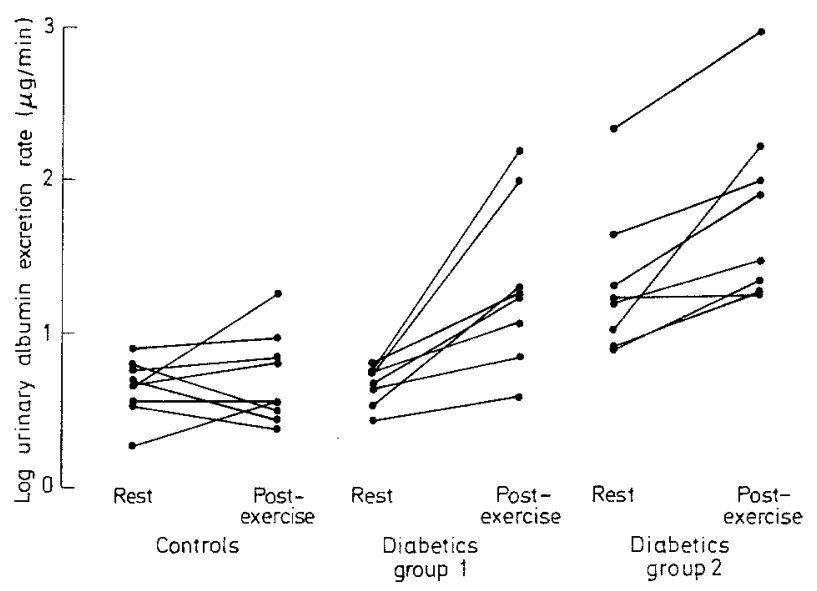

Fig. 2. Changes in log. urinary albumin excretion rates in the postexercise period in controls and in group 1 and 2 diabetics

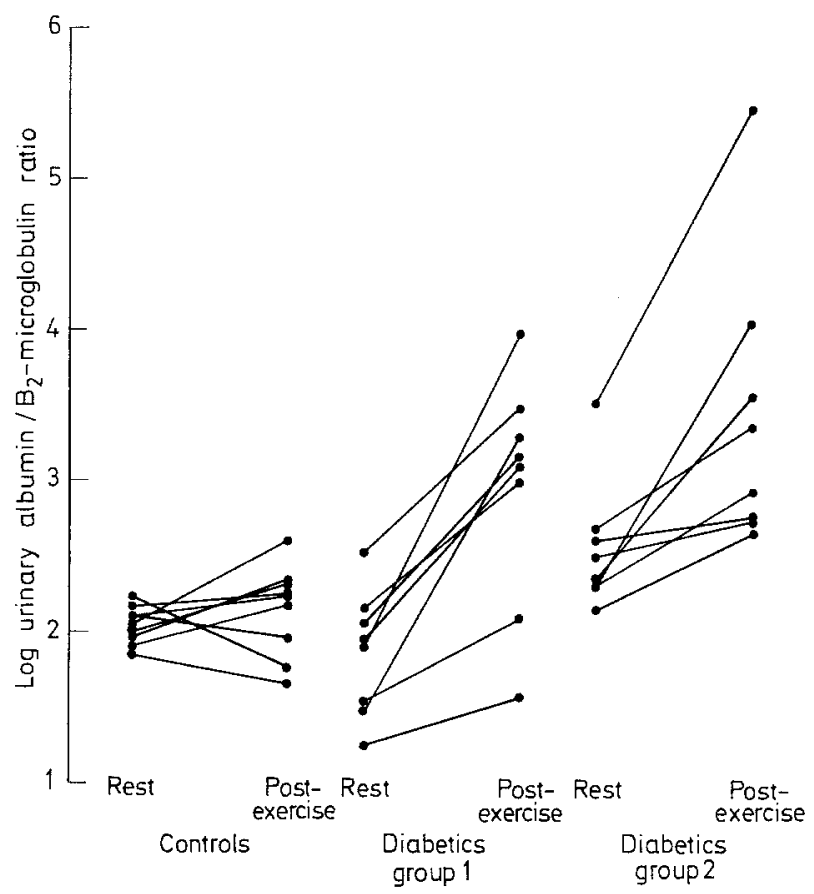

Fig. 3. Changes in log. urinary albumin $/ \beta_{2}$-microglobulin ratio in the post-exercise period in controls and in group 1 and 2 diabetics

trols and tended to decrease in the diabetics. These differences reached statistical significance in the two groups of diabetics in the post-exercise period $(\mathrm{p}<$ 0.05 ).

The calculated log-albumin $/ \beta_{2}$-microglobulin ratio was significantly higher at rest $(p<0.005)$ in group 2 diabetics compared with the controls. No difference was found between controls and group 1 diabetics. The exercise test produced, especially in the post-exercise period, a marked increase of logalbumin $/ \beta_{2}$-microglobulin ratio in both groups of diabetics $(p<0.005$ for group 1 and $p<0.01$ for group 2) but not in the controls (Fig. 3 ).

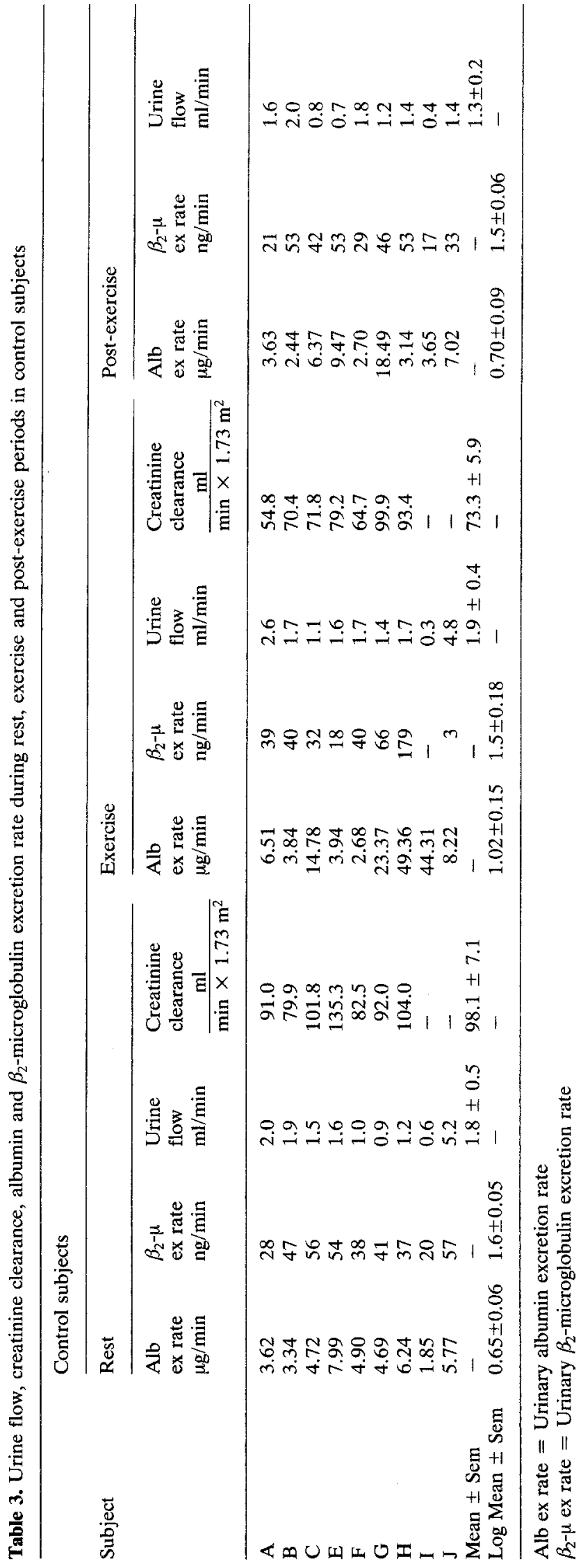




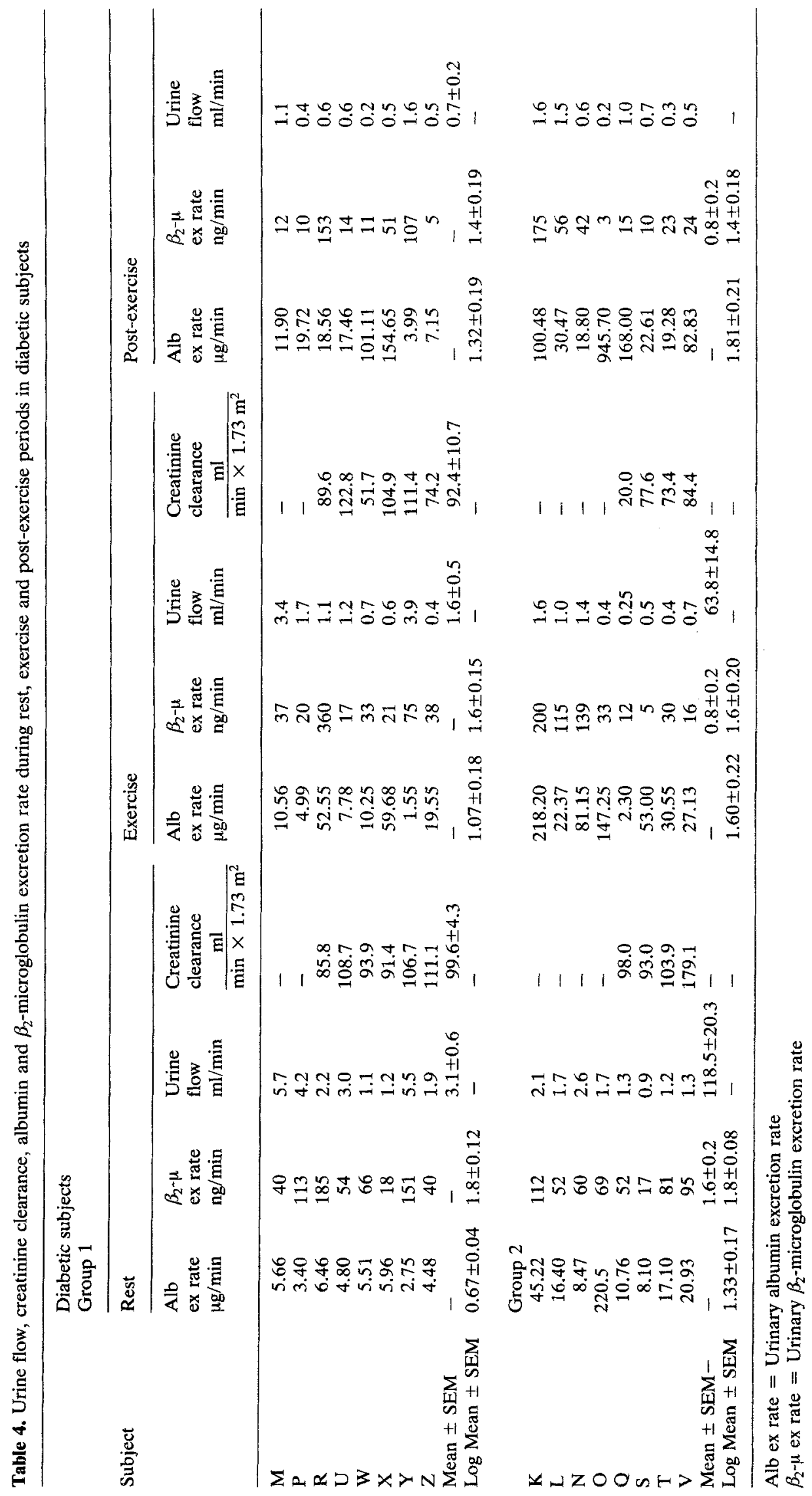


Table 5. Mean ( \pm SEM) pulse rate and systolic blood pressure at rest and during exercise in controls and diabetics

\begin{tabular}{|c|c|c|c|c|c|c|}
\hline & \multicolumn{2}{|c|}{ Pulse rate } & \multicolumn{4}{|c|}{$\begin{array}{l}\text { Systolic blood } \\
\text { pressure }\end{array}$} \\
\hline & 菟 & 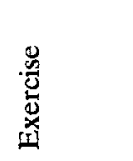 & 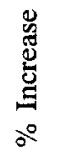 & 嶑 & 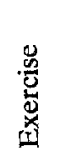 & 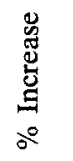 \\
\hline Controls & 69 & 131 & 93 & 111 & 134 & 21 \\
\hline$(n=9)$ & \pm 5 & \pm 7 & \pm 12 & \pm 4 & \pm 4 & \pm 4 \\
\hline Diabetics & 85 & 158 & 88 & 113 & 141 & 24 \\
\hline$(\mathrm{n}=16)$ & \pm 3 & \pm 4 & \pm 5 & \pm 2 & \pm 3 & \pm 2.5 \\
\hline Level of & & & & & & \\
\hline Significance & $\mathrm{p}<0.02$ & $\mathrm{p}<0.005$ & N.S. & N.S. & N.S. & N.S. \\
\hline
\end{tabular}

Both mean resting and maximal exercise pulse rates were significantly higher in the diabetics than in the controls, but the percent increase was similar in the two groups. The mean resting and the highest systolic blood pressure during exercise in the controls and in the diabetics did not differ significantly (Table 5 ). The results are not different when the diabetics are considered as two separate groups.

\section{Discussion}

The data presented in Tables 1 and 2 show that the two selected groups we have studied were well matched as to their physical characteristics. Diabetics were controlled within conventional limits as demonstrated by the mean random post-breakfast blood glucose of $13.4 \mathrm{mmol} / \mathrm{l}$. Their 24 hour urine volume was only slightly higher than that of the controls and none was ketonuric. The assumption made in this investigation, that the endogenous creatinine clearance approximated both the glomerular filtration rate (GFR) during rest and its relative change during exercise, is supported by the work of other authors $[10,11,12]$. Several practical problems are involved in the evaluation of GFR during exercise by any clearance method involving urine collections. The problems include low diuresis, the risk of incomplete emptying the bladder (even though voluntary samples for men in moderate diuresis have been found to give accurate clearance values $[5,13])$, and the relatively large methodological error for the clearance values from a single period collection. However, these do not invalidate the comparison between diabetics and controls.

The 24 hour albumin excretion rate was higher in our diabetic subjects, as a group, although half had excretion rates of albumin within the control range. The diabetics with higher urinary albumin excretions did not differ significantly from the remainder, although the slightly higher daily insulin doses and blood glucose values might suggest a form of diabetes more difficult to control. These findings indicate that, at least under ordinary conditions of life, many diabetics have an elevated excretion of albumin, while remaining negative to Albustix. In a similar group of diabetics who were admitted to hospital and strictly controlled Mogensen [2] found that albumin excretion rates were within the normal range, the implication being that very good control and, perhaps, hospital admission as an additional factor, may correct the mild disorder of albumin excretion.

Exercise induced proteinuria is a well recognised phenomenon [14, 15, 16], though the exact mechanism is unclear. Explanations offered include increased glomerular filtration pressure, decreased tubular reabsorption of protein and changes in glomerular permeability properties, but none at present are conclusively established.

Our findings confirm previous reports $[4,17]$ that moderately severe exercise produces a greater increase of albumin excretion rate in diabetics than in controls, and that the increased albuminuria is particularly evident in the post-exercise period. In the present study we have also made measurements of $\beta_{2}$-microglobulin excretion rates as an index of tubular function. More than $90 \%$ of the albumin filtered at the glomerulus is absorbed by the proximal tubule [18]; thus the exaggerated urinary excretion of albumin in the diabetics during exercise could be due either to increased transglomerular passage, decreased tubular reabsorption or both. Glomerular and tubular proteinuria can be distinguished by simultaneous measurements of $\beta_{2}$-microglobulin and albumin excretion rates [19]. The former is characterised by increased urinary albumin excretion, associated with nearly normal $\beta_{2}$-microglobulin excretion, while tubular proteinuria is characterised by increased $\beta_{2}$-microglobulin excretion associated with normal or slightly elevated albumin excretion [19]. An increase in the albumin $/ \beta_{2}$-microglobulin ratio may thus be accepted as index of glomerular proteinuria, while a decrease may be accepted as index of tubular proteinuria. There was no evidence of diminished tubular reabsorption of $\beta_{2}$-microglobulin during exercise and post-exercise periods, either in the diabetics or controls; in fact, its excretion rate tended to diminish, particularly in the diabetics. The higher resting albumin/ $\beta_{2}$-microglobulin ratio in group 2 diabetics suggests that these subjects had an elevated glomerular permeability to albumin even at rest. The marked increase in albumin $/ \beta_{2}$-microglobulin ratio found only in the diabetics clearly demonstrates that the elevation in albumin excretion rate 
produced by exercise is due to increased transglomerular passage of albumin. Thus the exaggerated albumin excretion in diabetics is characteristically a glomerular proteinuria. Our data also support other findings that tubular function is well maintained in insulin-treated non-proteinuric diabetics $[20,21]$. Exercise is thus a suitable provocation test to unmask underlying glomerular abnormalities in the kidney of diabetics and the period immediately following the end of the exercise seems to be the best indicator of such abnormalities.

Arterial hypertension is associated with increased urinary albumin excretion [22]. Blood pressure values were normal at rest in our diabetic subjects and during exercise systolic pressures did not rise more than in the controls, independently of the duration of diabetes. Karlefors [6] also observed no excess rise in systolic blood pressures in short-duration diabetics during exercise. This was the only group in his study with normal resting blood pressure; the mid- and long-duration diabetic groups both had raised resting and exercise pressures. Our diabetic patients had a higher mean pulse rate than the controls both at rest and during exercise. As they did not have any clinical evidence of autonomic neuropathy, this phenomenon may be ascribed to the insulin administration, for injection of insulin is known to significantly increase the pulse rate [23]. Moreover the percent increase in pulse rate was similar in the two groups and no correlation was found between pulse rate and albumin excretion rate. It is, therefore, unlikely that an 'abnormal' cardiovascular response to exercise was responsible for the increase in urinary albumin excretion in the diabetics. Urine flow can affect urine protein excretion $[16,24,25,26]$ and a positive correlation between urine flow and albumin excretion has been recently described $[27,28]$. We chose to administer an amount of water known, from other authors' work [10] and from preliminary experiments in our laboratory, not to induce forced diuresis. While urine output remained constant in the controls it decreased in the diabetics, presumably because of a reduction in the filtered load of glucose (urinary glucose excretion decreased in all diabetics after exercise (data not shown)). Thus an increase in urine flow cannot account for the exaggerated urinary albumin excretion produced by exercise in the diabetics. Increased GFR, associated with increased filtration fraction, has been postulated [14] to reflect an increase in glomerular filtration pressure, which would lead to an increase in protein excretion rates in diabetics during exercise. On the basis of our results we cannot exclude this possibility. However, although creatinine clearance decreased significantly with exercise in the controls, but did not do so in the diabetics as a group, the available data are too few to draw conclusions and, furthermore, a correlation between changes in albumin excretion and changes in creatinine clearance was not found. Whether an elevated GFR in the diabetics during exercise might be responsible for the exaggerated urinary albumin excretion remains an open question.

We did not find any correlation between duration of diabetes and albumin excretion rates, and the two diabetics of our group with a duration of diabetes of less than two years had, both at rest and after exercise, albumin excretion rates higher than the controls. These findings support the concept put forward by other investigators [21] that permeability properties of the glomerular membrane may be altered before thickening of the basement membrane can be demonstrated $[29,30]$. However, in diabetics with longer duration of disease the morphological changes could themselves be responsible for the altered permeselectivity to albumin.

The increased vascular permeability to albumin in diabetics present for some under ordinary conditions of life and for most under stress conditions, might contribute, as recently has been suggested [31], to the development of the structural changes which eventually lead to diabetic nephropathy.

Acknowledgements. We wish to thank Miss D. Williams and Mr. E. Regina for their skilful technical assistance, Dr. N. Veall and Dr.D. Pearson for the supply of ${ }^{125}$ I labelled albumin. Dr. A. Simmonds kindly performed the creatinine measurements.

\section{References}

1. Keen, H., Chlouverakis, C., Fuller, J., Jarrett, R. J.: The concomitants of raised blood sugar: studies in newly-detected hyperglycaemics. II, Urinary albumin excretion, blood pressure and their relation to blood sugar levels. Guy's Hosp. Rep. 118, 247-254 (1969)

2. Mogensen, C. E.: Urinary albumin excretion in early and longterm juvenile diabetes. Scand. J. Clin. Lab. Invest. 28, 183-193 (1971)

3. Balodimos, M.C., Chlouverakis, C., Gleason, R. E., Jarrett, R. J., Kahn, C. B., Keen, H., Soeldner, J.S.: Urinary albumin excretion in the offspring of conjugal diabetics. Lancet 1971 II, $239-242$

4. Mogensen, C.E., Vittinghus, E.: Urinary albumin excretion during exercise in juvenile diabetes. Scand. J. Clin. Lab. Invest. 35, 295-300 (1975)

5. Redigan, L. R., Robinson, S.: Effects of environmental heat, stress and exercise on renal blood flow and filtration rate. J. Appl. Physiol. 2, 185-191 (1949)

6. Karlefors, T.: Circulatory studies during exercise with particular reference to diabetics. Acta Med. Scand. [Suppl.] 180, 449 (1966)

7. Standard method adapted to the autoanalyser. Ref. Technicon Instrument Corp.; Technical Report No. AA II (1970)

8. Keen, H., Clouverakis, C.: An immunoassay method for urinary albumin at low concentrations. Lancet 1963 II, 913-914 
9. Evrin, P.E., Peterson, P.A., Wide, L., Berggaard, I.: Radioimmunoassay of $\beta_{2}$-microglobulin in human biological fluids. Scand. J. Clin. Lab. Invest. 28, 439-444 (1971)

10. Kachadorian, W. A., Johnson, R. E.: Renal response to various rates of exercise. J. Appl. Physiol. 28, 748-752 (1970)

11. Haugen, H. N., Blegen, E. M.: The true endogenous creatinine clearance. Scand. J. Clin. Lab. Invest. 5, 67-71 (1953)

12. Starlinger, H., Berghoff, A.: Untersuchungen über die Anwendbarkeit der endogenen Kreatinine-clearance im Vergleich zur Inulin-clearance in Ruhe- und Arbeitsversuchen bei gesunden Versuchspersonen. Int. Z. Angew. Physiol. 19, 194-200 (1962)

13. Chapman, C. B., Henschel, A., Minckler, J., Forsgreen, A., Keys, A.: Effect of exercise on renal plasma flow in normal male subjects. J. Clin. Invest. 27, 639-644 (1948)

14. Castenfors, J.: Renal function during exercise. With special reference to exercise proteinuria and the release of renin. Acta Physiol. Scand. 70 [Suppl. 293], 1-44 (1967)

15. Poortmans, J.R., Jeanloz, R. W.: Quantitative immunological determination of 12 plasma proteins excreted in human urine collected before and after exercise. J. Clin. Invest. 47, 386-393 (1968)

16. Taylor, A.: Some characteristics of exercise proteinuria. Clin. Sci. Mol. Med. 19, 209-217 (1960)

17. Mogensen, C. E.: Renal function changes in diabetes. Diabetes 25, 872-879 (1976)

18. Bourdeau, J.E., Carone, F. A.: Protein handling by the renal tubule. Nephron 13, 22-34 (1974)

19. Peterson, P. A., Evrin, P. E., Berggaard, I.: Differentiation of glomerular, tubular and normal proteinuria: determination of urinary excretion of $\beta_{2}$-microglobulin, albumin and total protein. J. Clin. Invest. 48, 1189-1198 (1969)

20. Farr, M., Wardle, E. N., Wilkinson, K.: Lysozymuria in diabetes. Br. Med. J. 1976 I, 624-625

21. Parving, H.H., Noer, I., Deckert, I., Evrin, P. E., Nielsen, S. L., Lyngsøe, J., Morgensen, C. E., Rørth, M., Svendsen, P. Aa., Trap-Jensen, J., Lassen, N. A.: The effect of metabolic regulation on microvascular permeability to small and large molecules in short-term juvenile diabetics. Diabetologia 12, 161-166 (1976)
22. Parving, H. H., Jensen, H.E., Mogensen, C. E., Evrin, P. E.: Increased urinary albumin-excretion rate in benign essential hypertension. Lancet 1974 I, 1190-1192

23. Page, M. McB., Smith, R. B. W., Watkins, P. J.: Cardiovascular effect of insulin. Br. Med. J. 1976 I, 430-432

24. Roscoe, M. H.: Proteinuria in the nephrotic syndrome and in hypertensive renal failure. Clin. Sci. Mol. Med. 21, 141-150 (1961)

25. Brug, J.: Studies on proteinuria. Acta Med. Scand. 76, 1-151 (1936)

26. Pillay, V.K. G., Gandhi, V.C., Sharma, B.K., Smith, E.C. Dunea, G.: Effect of hydration and furosemide given intravenously on proteinuria. Arch. Intern. Med. 130, 90-92 (1972)

27. Jarrett, R. J., Verma, N.P., Keen, H.: Urinary albumin excretion in normal and diabetic subjects. Clin. Chim. Acta 71, 55-59 (1976)

28. Viberti, G.C., Jarrett, R.J., Keen, H.: Diuresis and urinary albumin excretion: the effect of hydration. A study in insulindependent diabetics and normal controls (Abstract). Diabetologia 13, 438 (1977)

29. Osterby, R.: Morphometric studies of the peripheral glomerular basement membrane in early juvenile diabetes. I. Development of initial basement membrane thickening. Diabetologia 8, 84-92 (1972)

30. Osterby, R.: Early phases in the development of diabetic glomerulopathy. Acta Med. Scand. 197 [Suppl. 574], 13-82 (1975)

31. Williamson, J.R., Kilo, C.: Current status of capillary basement membrane disease in diabetes mellitus. Diabetes 26, 65-73 (1977)

Received: July 13, 1977, and in revised form: November 25, 1977

R. J. Jarrett

Unit for Metabolic Medicine

Guy's Hospital Medical School

London Bridge, SE1 9 RT

England 